\title{
Aspectos micromorfológicos da epiderme das brácteas em espécies de Scleria Berg. - Cyperaceae da Serra do Cipó
}

Micromorphological aspects of the bracts epidermis in species of Scleria Berg. - Cyperaceae from Serra do Cipó

\author{
Vera Fatima Gomes Alves Pereira Lima ${ }^{1,2,4}$ \& Nanuza Luiza de Menezes ${ }^{3}$
}

\begin{abstract}
Resumo
As microestruturas da epiderme foliar são consideradas de grande valor na taxonomia de vários grupos de Cyperaceae e a deposição da sílica é um dos aspectos considerados de maior relevância. Uma proporção variável das células epidérmicas apresenta corpos silicosos, quase sempre com formato cônico e, relacionados, às regiões costais da folha. Os corpos silicosos podem ter formatos diferentes, como os conglomerados de sílica. Nas espécies aqui analisadas, a sílica é observada formando cones, conglomerados e também, impregnando as paredes das células epidérmicas, inclusive, dos estômatos e dos tricomas. Com base nas informações obtidas conclui-se que os caracteres anatômicos da epiderme das brácteas em espécies de Scleria ocorrentes na Serra do Cipó oferecem alguns subsídios, como o formato dos corpos silicosos, a distribuição dos estômatos e a presença ou ausência de tricomas (curtos e longos), que podem ser utilizados como caracteres diagnósticos para delimitação taxonômica.
\end{abstract}

Palavras-chave: sílica, estômatos, tricomas.

\begin{abstract}
The leaf epidermis microstructures are considered of great value in several Cyperaceae groups taxonomy and the silica deposition is one of the aspects with great relevance. A variable proportion of the epidermis cells presents silica bodies, almost always with conical shape and, related to the leaf costal areas. The silica bodies assume different shapes as the silica conglomerates. In the species analyzed, the silica forms cones, conglomerates and also, appears impregnating the epidermis cell walls, including stomata and hairs. Based on this paper information, the bracts epidermis in the studied species of Scleria offers some subsidies, like silica bodies shape, stomata distribution and presence or absence of hairs (short and long) that can be used as diagnostic characters in taxonomic delimitation.
\end{abstract}

Key words: silica, stomata, hairs.

\section{Introdução}

Estudos anatômicos em Cyperaceae têm sido desenvolvidos, principalmente, sob o aspecto taxonômico e a análise da estrutura foliar constitui um parâmetro indispensável na taxonomia do grupo (Metcalfe 1971; Standley 1990; Muasya et al. 2000; Alves et al. 2002; Simpson et al. 2003; Arruda \& Neves 2005; Martins et al. 2008).
Comparativamente com outros aspectos da morfologia das Cyperaceae, os estudos micromorfológicos com o microscópio eletrônico de varredura são relativamente escassos. Destacam-se os trabalhos de Metcalfe (1971), Tovoinen \& Timonen (1976), Franklin (1979), Rajbhandari \& Ohba (1988), Standley (1990), Menapace (1990), Araújo \& Longui-Wagner (1997), Martins et al. (2008), Prata

\footnotetext{
${ }^{1}$ Parte da Tese de Doutorado da primeira autora, Programa de Pós-Graduação em Botânica da Universidade de São Paulo, SP.

${ }^{2}$ Universidade Guarulhos, Praça Teresa Cristina s/n, Centro, 07023-070, Guarulhos, SP, Brasil.

${ }^{3}$ Universidade de São Paulo, Depto. Botânica, Inst. Biociências, 05508-900, São Paulo, SP, Brasil.

${ }^{4}$ Autor para correspondência: vfgalves@yahoo.com.br
} 
et al. (2008) e Honaine et al. (2009), a maioria deles relacionada à superfície do aquênio. Neste aspecto, o gênero Carex é um dos mais estudados (Menapace \& Winjek 1985; Salo et al. 1994).

As microestruturas da epiderme foliar são consideradas de grande valor na taxonomia de vários gêneros de Cyperaceae, pois são frequentemente utilizadas na delimitação intraespecífica. Em tais estudos, os aspectos considerados de maior relevância, em geral, dizem respeito à configuração das paredes anticlinais das células epidérmicas, às estrias epicuticulares, à densidade, comprimento e largura dos estômatos (Standley 1987) mas, principalmente, à deposição de sílica, já que a ocorrência e a localização desta última parecem ser precisas dentro da família Cyperaceae (Mehra \& Sharma 1965; Prychid et al. 2004).

Em Cyperaceae, a forma de deposição da sílica nas células epidérmicas tem sido considerada de grande valor na diagnose de gêneros e espécies (Metcalfe 1971; Deshan 1998; Mehra \& Sharma 1965). Os primeiros estudos sobre a deposição de sílica nas Cyperaceae foram os de Duval-Jouve (1872 apud Prychid et al. 2004), Westermaier (1884 apud Mehra \& Sharma 1965), Holm (1899), Chermazon (1926) e Haberlandt (1928). Baseado no formato que os depósitos de sílica assumem no interior das células, Metcalfe (1963) propõe uma classificação para esses corpos silicosos, ou seja, em cone, em conglomerados, dentre outros. Posteriormente, Metcalfe (1971) cita a ocorrência de corpos silicosos em vários gêneros da família, utilizando o critério acima exposto associado a outros, para a caracterização destes grupos.

O objetivo do presente trabalho é analisar as epidermes das brácteas em espécies de Scleria ocorrentes na Serra do Cipó e, em especial, localizar a sílica nas células epidérmicas verificando possíveis variações na deposição da mesma.

\section{Material e Métodos}

As sete espécies de Scleria Berg. analisadas no presente estudo - $S$. bracteata Cav., $S$. distans Poir., S. latifolia Sw., S. leptostachya Kunth, S. microcarpa Nees ex Kunth, S. scabra Willd e S. secans (L.)_Urb. - provêm da Serra do Cipó (Minas Gerais). Scleria bracteata, S. latifolia e $S$. secans ocorrem em mata ripária; $S$. distans e $S$. leptostachya em campos arenosos; e S. microcarpa e $S$. scabra em capão e de cerrado.

O material encontra-se depositado nos Herbários SPF - S. bracteata (M. Alves et al. 2120),
S. latifolia (M. Alves et al. 2123), S. leptostachya (M. Alves et al. 2163), S. distans (M. Alves et al. 2174), S. microcarpa (M. Alves et al. 2144) e $S$. scabra (M. Alves et al. 2181) - e SP - S. secans (A.P. Prata et al. 1165). Parte do material foi fixada em Allen-Bouin (Berlyn \& Miksche 1976) e conservada em etanol $70^{\circ}$ G.L. (Jensen 1962) visando posteriores análises morfo-anatômicas e histoquímicas. Para as análises micromorfológicas das epidermes as amostras foram fixadas em glutaraldeído (Kraus et al. 1998).

Para a análise das epidermes em microscopia fotônica, fragmentos da lâmina foliar das brácteas foram colocados em solução de ácido nítrico a $10 \%$ (Ghouse \& Yunus 1972) e aquecidos em placa aquecedora, até a dissociação. Posteriormente, as epidermes foram lavadas em água destilada e coradas em safranina $1 \%$ em etanol $50 \%$ e fucsina básica $0,05 \%$ em etanol 50\% (Kraus et al. 1998) e montadas em glicerina 50\%. Para a observação da sílica foram submetidos à coloração pelo fenol e óleo de cravo, seguindo Johansen (1940).

As análises micromorfológicas da epiderme foram efetuadas com material previamente preparado, de acordo com os procedimentos de Berlyn e Miksche (1976) e Silveira (1989). As amostras foram desidratadas em série etílica, com passagem pelo ponto crítico de $\mathrm{CO}_{2}$ e montagem em stubs, com metalização em ouro. As imagens do material foram observadas e fotografadas em Microscópio Eletrônico de Varredura SEM 505 Philips. Para tal, fragmentos de brácteas foram montados de maneira a permitir observações em vista frontal das duas faces da epiderme, bem como, em secção transversal para algumas espécies.

Para uma análise mais detalhada da sílica, fragmentos das brácteas foram submetidos ao ponto crítico de $\mathrm{CO}_{2}$, montados em stubs e recobertos com carbono, utilizando-se a técnica da evaporação de carbono em alto vácuo. As observações foram realizadas em Microscópio Eletrônico de Varredura modelo LEO 440i, através de elétrons retro-espalhados (scattering electron microscopy - QBSD) (Brandenberg et al. 1985) no Instituto de Geociências da USP.

Por serem as brácteas os órgãos foliáceos expostos à luz que ocorrem no escapo das ciperáceas, justifica-se o uso das mesmas no presente estudo, e não dos catafilos, que são as folhas propriamente ditas, mas que ocorrem subterraneamente no rizoma. 


\section{Resultados}

Em todas as espécies estudadas identificam-se, em ambas as faces da epiderme foliar, ondulações nas paredes anticlinais das células epidérmicas comuns e, em tais ondulações, percebe-se a presença de impregnações de sílica, detectada pelo método QBSD (Fig. 1a-e).

Quando observadas em vista frontal, as células epidérmicas com cones de sílica formam fileiras longitudinais, à semelhança dos estômatos (Fig. 2a-c). Estes cones se depositam sobre a parede periclinal interna de células epidérmicas comuns da face abaxial, posicionadas junto às fibras do mesofilo, geralmente, associadas às unidades vasculares e, observa-se que, o ápice do cone se direciona para a parede periclinal externa e a base se posiciona sobre a parede periclinal interna da célula epidérmica (Fig. 2e). Na face adaxial da epiderme foliar das espécies Scleria distans e $S$. leptostachya observam-se, além dos cones, os chamados conglomerados de sílica (Fig. $2 \mathrm{~d}, \mathrm{f}, \mathrm{g})$. Estes se dispõem junto às paredes anticlinais de células adjacentes e observam-se dois ou, às vezes, três destes conglomerados, separados apenas pelas paredes anticlinais destas células (Fig. 2d).
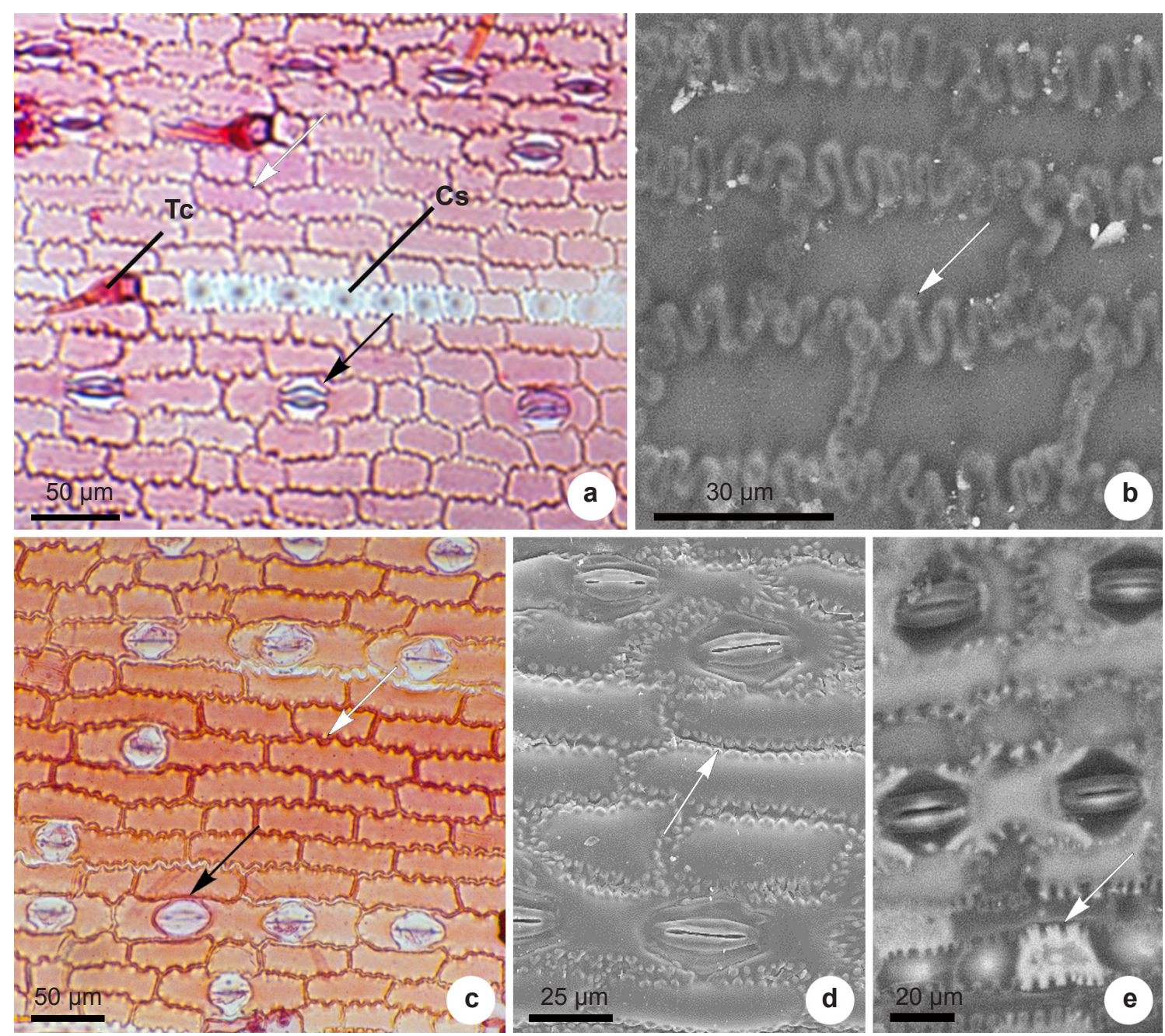

Figura 1 - a-e. Sinuosidade e impregnação de sílica nas paredes das células epidérmicas em vista frontal. - a. face adaxial de Scleria microcarpa; b. S. secans.; c. face abaxial de S. distans; d. S. latifolia; e. S. secans. Cs = corpo de sílica; seta branca $=$ sinuosidade e impregnação de sílica na parede celular; seta preta = estômato; $\mathrm{Tc}=$ tricoma curto. Figure 1 - a-e. Sinuosity and silica impregnation on the cell walls in front view - a. adaxial face of Scleria microcarpa; b. S. secans; c. abaxial face of S. distans; d. S. latifolia; e. S. secans. Cs = silica body; white arrow = sinuosity and silica impregnation on the cell wall; black arrow $=$ stomata; $\mathrm{Tc}=$ short hair. 

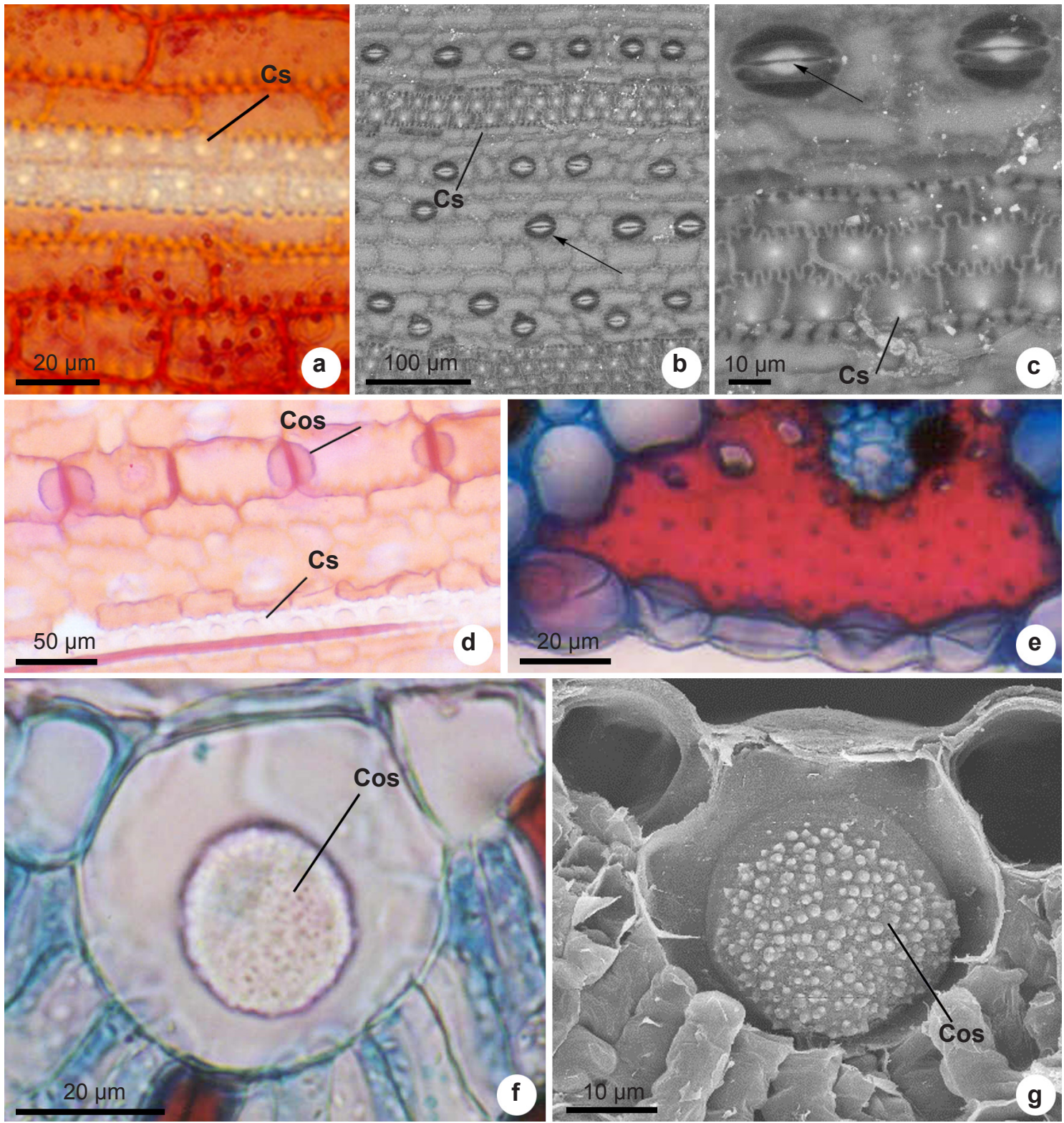

Figura 2 - a-g. Sílica em vista frontal e em secção transversal. - a. vista frontal da face abaxial de Scleria latifolia; b. S. distans; c. vista frontal da face adaxial de S. leptostachya; d. S. distans; e. secção transversal da face abaxial de $S$. leptostachya; f. da face adaxial de S. distans; g. S. leptostachya. Cs = corpo de sílica; Cos = conglomerado de sílica; seta = impregnação de sílica na parede celular).

Figure 2 - a-g. Silica in front view and in cross section. a. front view on the abaxial face of Scleria latifolia; b. S. distans; c. front view on the adaxial face of S. leptostachya; d. S. distans; e. cross section on the abaxial face of S. leptostachya; f. on the adaxial face of S. distans; g. S. leptostachya. $\mathrm{Cs}=$ silica body; $\mathrm{Cos}=$ silica conglomerate; arrow = silica impregnation on the cell wall.

Os estômatos são do tipo paracítico, dispõemse em fileiras longitudinais e encontram-se restritos à face abaxial da epiderme nas espécies Scleria bracteata, S. latifolia, S. secans e S. scabra (Fig. 3b-d), enquanto que nas espécies Scleria distans,
S. leptostachya e $S$. microcarpa são encontrados em ambas as faces (Figs. 1a, 1c, 3a, 4d). Em todas as espécies, as paredes voltadas para o ostíolo das células-guarda apresentam-se impregnadas de sílica, detectada pelo método QBSD (Fig. 2c). 
$\mathrm{Na}$ face adaxial verifica-se uma grande quantidade de tricomas tectores curtos, unicelulares, com extremidade ponteaguda e silicificados na espécie Scleria bracteata (Fig. 4a) e uma quantidade menor dos mesmos nas espécies $S$. secans (Fig. 4b) e $S$. scabra; na face abaxial, Scleria bracteata exibe uma grande quantidade de tricomas tectores longos, unicelulares, com extremidade ponteaguda e silicificados (Fig. 4c); em S. microcarpa verificase uma grande quantidade de tricomas tectores curtos e longos, unicelulares, com extremidade ponteaguda e silicificados em ambas as faces da epiderme (Fig. 1a e 4d); e nas espécies $S$. distans, $S$. leptostachya e $S$. latifolia não são observados tricomas na epiderme foliar.

\section{Discussão}

Em relação aos aspectos estruturais da epiderme das brácteas, as características apontadas para as espécies em estudo estão de acordo com as descritas por Metcalfe (1971) para o gênero Scleria e para a família Cyperaceae, muito embora este e a grande maioria dos outros autores se refiram às brácteas, como sendo folhas.
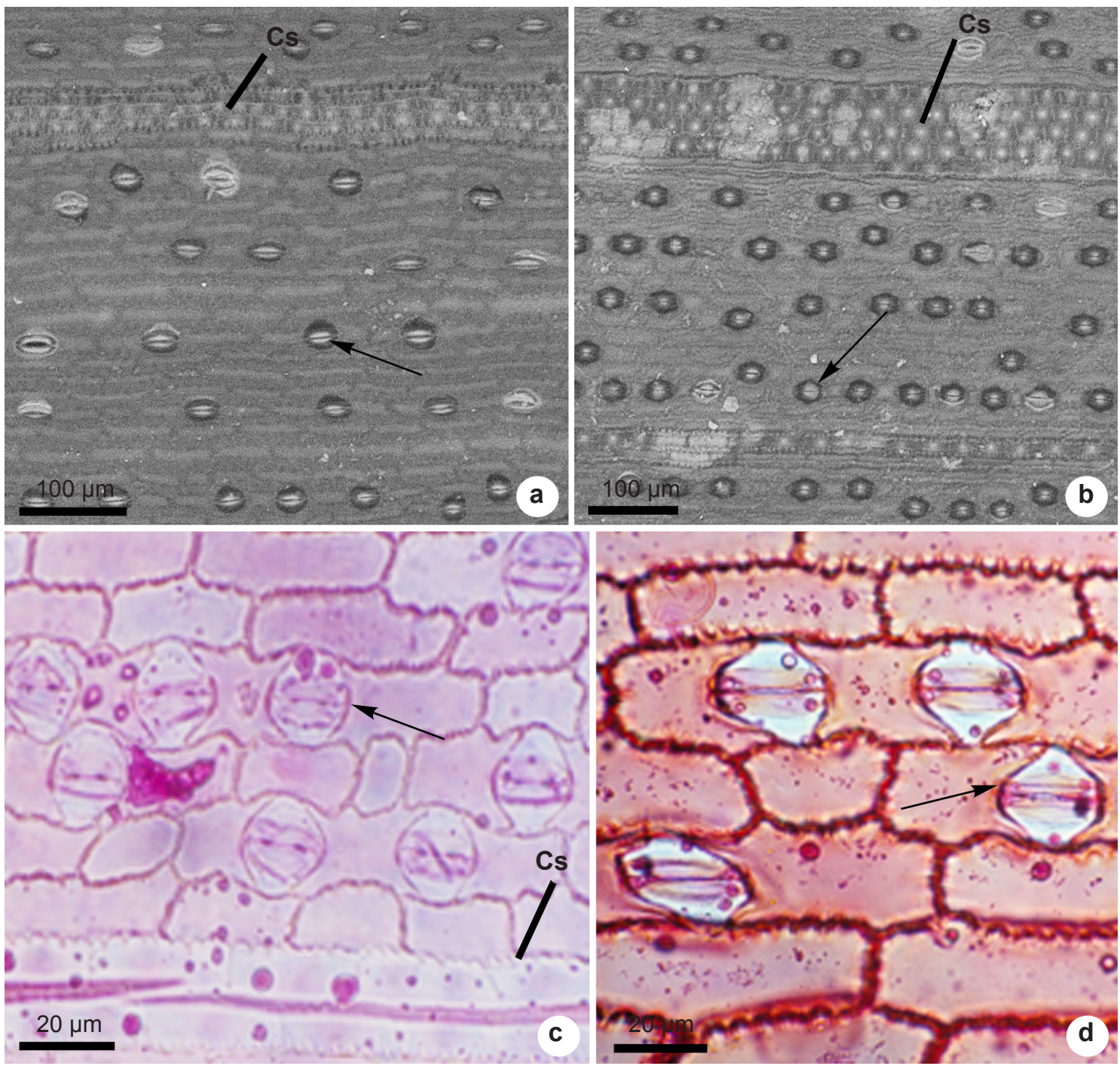

Figura 3 - a-d. Estômatos em vista frontal - a. face adaxial de Scleria distans. b-d. face abaxial de S. scabra (b,c) e de S. latifolia (d). Cs = corpo de sílica; seta = estômato.

Figure 3 - a-d. Stomata in front view - a. adaxial face of Scleria distans. b-d. abaxial face of S. scabra $(\mathrm{b}, \mathrm{c})$ and S. latifolia $(\mathrm{d})$. Cs = silica body; arrow $=$ stomata. 

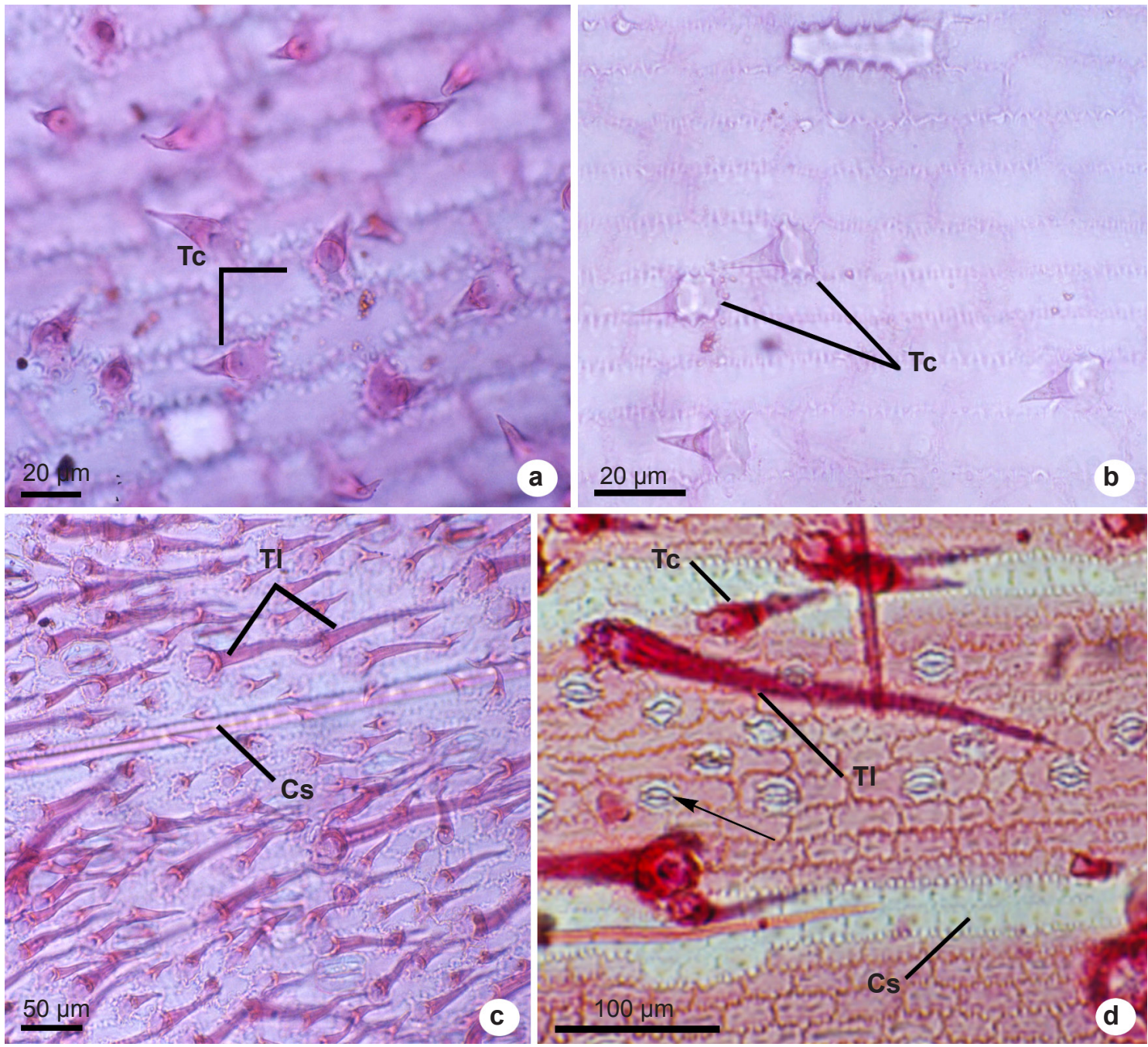

Figura 4-a-d. Tricomas em vista frontal - a. face adaxial de Scleria bracteata; b. face adaxial de $S$. secans; c. face abaxial de S. bracteata; d. face abaxial de $S$. microcarpa $. \mathrm{Cs}=$ corpo de sílica; $\mathrm{Tc}=$ tricoma curto; $\mathrm{Tl}=$ tricoma longo; seta = estômato. Figure 4 - a-d. Hairs in front view - a. adaxial face of Scleria bracteata; b. adaxial face of S. secans; c. abaxial face of S. bracteata; adaxial face of $S$. microcarpa $. \mathrm{Cs}=$ silica body; $\mathrm{Tc}=$ short hair; $\mathrm{Tl}=$ long hair; arrow $=$ stomata.

Neste trabalho foi confirmada a relevância dos aspectos relacionados com a epiderme foliar na taxonomia de Cyperaceae, fato já demonstrado por Araújo \& Longhi-Wagner (1997) e Alves et al. (2002). A sinuosidade apresentada pelas paredes das células epidérmicas, observada também em espécies de Scleria, foi explicada por Avery (1933), como sendo resultante de estresse sofrido pela planta durante o desenvolvimento da folha. Por outro lado, Pyykkö (1966) afirma que, tal sinuosidade, está relacionada a plantas que se desenvolvem em ambientes úmidos e sombreados. Uma vez que algumas das espécies coletadas se localizam em solos brejosos e outras, em solos com uma boa oferta de água, devido a constante proximidade com riachos, pode-se considerar que estas plantas estejam se desenvolvendo em ambientes com um mínimo de umidade no solo, o que possivelmente explica a sinuosidade nas paredes celulares, concordando assim, com Pyykkö (1966). Entretanto, conforme já mencionado por Arruda \&Neves (2005), a sinuosidade observada nas paredes de células epidérmicas pode indicar a manifestação de um caráter familiar, comum às espécies de Cyperaceae, que ocorrem em ambientes extremamente diversos. 
Corpos silicosos de formatos e tamanhos variados ocorrem em folhas de diversos grupos de monocotiledôneas e sempre em tecidos bem definidos. Sua forma e posição não são totalmente influenciadas pelas condições ambientais, mas são geneticamente controladas e podem exibir considerável potencial taxonômico (Prychid et al. 2004). De acordo com Hodson \& Evans (1995) a sílica é um importante componente dos solutos minerais, sendo o segundo elemento mais abundante da crosta terrestre, após o oxigênio. Mehra \& Sharma (1965) afirmam que, uma proporção variável das células epidérmicas de folhas e caules de Cyperaceae é composta por células que apresentam corpos silicosos, especialmente aquelas células dispostas junto às fibras do mesofilo. Nesta situação, quase sempre têm forma cônica e sua base está em contato com a parede periclinal interna da célula epidérmica, enquanto o ápice está voltado em direção à parede periclinal externa da mesma célula, conforme observado na epiderme de Trilepis lhotzkiana Nees e T. ciliatifolia $T$. Koyama (Arruda \& Neves 2005), na epiderme de Cyperus maritimus Poir. (Martins et al. 2008) e de Cyperus odoratus L., Pycreus macrostachyos (Lam.) J. Raynal e Oxycaryum cubense (Poepp. \& Kunth) Palla (Leite et al. 2009). O número de corpos cônicos de sílica varia de 1 a 16 ou mais por célula, sendo algumas vezes útil para propósitos diagnósticos (Metcalfe 1969). Em algumas espécies é observado que, um cone de sílica pode estar rodeado por vários cones menores, chamados de satélites (Metcalfe 1971). De acordo com Honaine et al. (2009), caracteres qualitativos e quantitativos relacionados aos cones de sílica podem ser utilizados na distinção de grupos em Cyperaceae.

Em Scleria distans e S. leptostachya, entretanto, a sílica também é observada em células das regiões intercostais. Nestas células, os corpos silicosos assumem formatos diferentes daqueles encontrados nas células das regiões costais, o que corrobora a afirmação de Prychid et al. (2004). Um exemplo são os conglomerados de sílica que se formam junto às paredes anticlinais de células adjacentes, paralelas no sentido longitudinal assim como foi observado por Govindarajalu $(1969,1974)$, Metcalfe (1971) e Prychid et al. (2004) nas Cyperaceae em geral, além de Bromeliaceae, Poaceae, Cyperaceae, Thurniaceae, Rapateaceae, Centrolepidaceae, Ecdeiocoleaceae e Joinvilleaceae.
Holm (1899) afirmou que, em Scleria, algumas incrustrações de sílica muito peculiares podem ser verificadas sobre as paredes, por ele denominadas radiais, de células buliformes e formando massas granulares transparentes, que variam na forma e tamanho, exatamente como aqui observado.

Nas espécies em estudo, observamos também a sílica nas paredes das células epidérmicas, das células estomáticas e dos tricomas, o que corrobora o observado por Prychid et al. (2004). Segundo as autoras, a sílica pode ser observada formando depósitos internos na parede celular, entre a parede celulósica e a membrana plasmática.

O papel fisiológico das deposições silicosas em folhas têm despertado o interesse de diversos autores. McNaughton \& Tarrants (1983) consideram que a presença de sílica nas folhas talvez as protejam do ataque de fungos patogênicos e de herbívoros em geral, além de neutralizar os efeitos tóxicos de certos elementos minerais. Campos \& Laboriau (1969) presumem que a sílica desempenha importante função em relação ao balanço hídrico, às trocas térmicas e à reflexão da radiação. Lanning et al. (1958) e Moore (1984) consideram a sílica como um elemento estrutural complementar, contribuindo para a sustentação vegetal. Em Cyperus alternifolius foi observado que o silício regula a absorção de nutrientes minerais pelas células silicosas (Soni et al. 1972), o que possivelmente também ocorre com as espécies de Scleria em estudo, uma vez que nos ambientes da Serra do Cipó o solo é caracteristicamente pobre em nutrientes minerais (Santos et al. 2011). Mehra \& Sharma (1965) também afirmam que a sílica é mais comum no órgão ou parte do órgão que amadurece primeiro, como por exemplo, a lâmina foliar e que, a menos que a planta careça de folhas, a sílica é mais comum nestes órgãos do que em caules. De acordo com Prychid et al. (2004), a sílica é mais raramente encontrada em raízes. Em muitas espécies, as folhas de plantas mais velhas contêm quantidades maiores de sílica, em relação às folhas mais jovens e, plantas da mesma espécie, crescendo em solos diferentes, podem exibir níveis diferenciados de sílica (Prychid et al. 2004). Ainda de acordo com estas autoras, os corpos de sílica presentes em células epidérmicas atuam na redução da transpiração foliar, tornando mais eficiente o uso da água. Tal caráter é importante para as espécies que se desenvolvem na Serra do Cipó, onde se observa a necessidade de retenção de água (Joly 1970). 
A presença de estômatos em ambas as faces da epiderme é observada em três das sete espécies em estudo (Scleria distans, S. leptostachya e $S$. microcarpa). Gurevitch et al. (2009) afirmam que muitas plantas nativas de ambientes áridos são anfiestomáticas e que esta característica, especialmente quando aliada à presença de mesofilo isobilateral, provavelmente indica uma adaptação aos altos níveis de luminosidade disponível nestes ambientes. Uma vez que as três espécies referidas estão constantemente expostas a altos níveis de luminosidade, possivelmente a presença de estômatos em ambas as faces possa ser indicativo de um mecanismo adaptativo eficiente para o estabelecimento dos espécimes, pois otimizaria a fotossíntese.

Em relação à $S$. scabra, espécie submetida a condições de estresse semelhantes àquelas observadas para $S$. microcarpa, a presença de estômatos está restrita à face abaxial da epiderme, assim como é observado para as espécies Scleria bracteata, S. latifolia e $S$. secans, que ocorrem em ambientes mais úmidos e sombreados. Parkhurst (1978) afirma que tal característica é mais comum em plantas de regiões úmidas. De acordo com Cutter (1986), condições ambientais momentâneas, como uma possível diminuição da intensidade luminosa, podem afetar a formação e a distribuição dos estômatos na planta, o que provavelmente se aplica ao caso de $S$. scabra em seu ambiente de coleta.

Nas demais espécies de Scleria aqui analisadas (S. bracteata, S. latifolia e $S$. secans), ocorrentes em matas ripárias da Serra do Cipó, ambientes considerados mais úmidos e sombreados, os estômatos ocorrem apenas na face abaxial da epiderme, característica esta, considerada mais comum em plantas de regiões úmidas (Parkhurst 1978).

A presença de tricomas na epiderme foliar é uma característica comum na família Cyperaceae (Haines \& Lye 1983). Em geral, são unicelulares, de vários tipos, comprimento variável, com parede celular pouco espessada e flexível ocorrendo, especialmente, nas margens da folha. Podem apresentar valor diagnóstico em nível de espécie (Metcalfe 1971; Arruda \& Neves 2005; Martins et al. 2008).

A ocorrência de tricomas unicelulares simples é comum dentre as espécies aqui analisadas, exceto em Scleria latifolia, S. distans e S. leptostachya que se apresentam glabras.
Dentre as espécies analisadas observamse, além dos corpos cônicos de sílica e da sílica presente junto às paredes celulares da epiderme, a silicificação dos tricomas, o que mostra pouco valor diagnóstico, em função da ampla ocorrência destes tricomas silicificados na família (Metcalfe 1971). De acordo com Campos \& Laboriau (1969), estes tricomas estariam diretamente relacionados com a reflexão da radiação. Nas espécies glabras, especialmente em $S$. distans e $S$. leptostachya, a ausência de tricomas é compensada pela presença dos conglomerados de sílica em algumas células buliformes das regiões intercostais enquanto que, em $S$. latifolia, a presença de sílica nas paredes das células epidérmicas e nos cones parece ser suficiente já que, esta espécie, ocorre sempre em locais sombreados de mata ripária.

Com base nas informações obtidas concluise que os caracteres anatômicos da epiderme das brácteas das espécies de Scleria estudadas na Serra do Cipó oferecem alguns subsídios, como o formato dos corpos silicosos, a distribuição dos estômatos e a presença ou ausência de tricomas (curtos e longos), que podem ser utilizados como caracteres diagnósticos.

\section{Agradecimentos}

A autora agradece ao Conselho Nacional de Desenvolvimento Científico e Tecnológico (CNPq), a bolsa de Doutorado concedida.

\section{Referências}

Alves, M.; Estelita, M.E.; Wanderley, M.G. \& Thomas, W. 2002. Aplicações taxonômicas da anatomia foliar das espécies brasileiras de Hypolytrum Rich. Cyperaceae. Revista Brasileira de Botânica 25: 1-9.

Araujo, A. \& Longhi-Wagner, H. 1997. Anatomia foliar e micromorfologia da superfície do fruto na taxonomia de Cyperus L. Iheringia Série Botânica 48: 103-120.

Arruda, R. \& Neves, L. de J. 2005. Anatomia foliar de Trilepis lhotzkiana Nees e Trilepis ciliatifolia T. Koyama (Cyperaceae). Acta Botânica Brasílica 19: 889-897.

Avery, G. 1933. Structure and development of the tobacco leaf. American Journal of Botany 20: 565-592.

Berlyn, J.P. \& Mikche, J.P. 1976. Botanical Microtechnique and Cytochemistry. Iowa State Press, Arnes. 326p.

Brandenberg, D.M.; Russell, S.D.; Estes, J.R. \& Chissoe, W.F. 1985. Backscattered electron imaging as a technique for visualizing silica bodies in grasses. Scanning Electron Microscopy 4: 1509-1517. 
Campos, A.C. \& Labouriau, L.G. 1969. Corpos silicosos de gramíneas dos cerrados. II. Pesquisa Agropecuária Brasileira 4:143-151.

Chermezon, M.H. 1926. Sur la feuille de certaines espèces de Scleria. Révue Générale de Botanique 38: 337-353.

Cutter, E. 1986. Anatomia vegetal. Parte I: Células e tecidos. $2^{\text {a }}$ ed. Rocca, São Paulo. 304p.

Deshan, D. 1998. The studies en phytolith system de Cyperaceae. Guihania 18: 204-208.

Franklin, E.F. 1979. A note on the hairy achenes of four African species of Scleria Bergius (Cyperaceae). Botanical Journal of the Linnean Society 79: 333-341.

Ghouse, A. \& Yunus, M. 1972. Preparations of epidermal peels from leaves of Gymnosperm by treatment with 60\% HNO3. Stain Technology 47: 322- 325.

Govindarajalu, E. 1969. The systematic anatomy of South Indian Cyperaceae: Cyperus L. subgen. Kyllinga (Rottb.) Suringar. Botanical Journal of the Linnean Society 62: 41-58.

Govindarajalu, E. 1974. The systematic anatomy of south Indian Cyperaceae: Cyperus L. subgen. Juncellus, Cyperus subgen. Mariscus and Lipocarpha R. Br. Botanical Journal of the Linnean Society 68: 235-266.

Gurevitch, J.; Scheiner, S.M. \& Fox, G.A. 2009. Ecologia Vegetal. Artmed, Porto Alegre. 592p.

Haberlandt, G. 1928. Physiological Plant Anatomy. Mc Millan and Co, London. 777p.

Haines, R.W. \& Lye, K.A. 1983. The Sedges and Rushes of East Africa: A flora of the families Juncaceae and Cyperaceae in East Africa, with a particular reference to Uganda. East African Natural History Society, Nairobi. 404p.

Hodson, M.J. \& Evans, D.E. 1995. Aluminium/ silicon interactions in higher plants. Journal of Experimental Botany 46: 161-171.

Holm, T. 1899. Studies in the Cyperaceae. X. Fimbristylis Vahl.: an anatomical treatise of north american species. American Journal of Science 42: 435-450.

Honaine, M.F., Zucol, A.F. \& Osterrieth, M. L. 2009. Phytolith analysis of Cyperaceae from the Pampean region, Argentina. Australian Journal of Botany 57: 512-523.

Jensen, W.A. 1962. Botanical Histochemistry. Principles and Practice. W.H. Freeman, San Francisco. 408p.

Johansen, D.A. 1940. Plant Microtechnique. McGrawHill Book Co. Inc., New York. 523p.

Joly, A.B. 1970. Conheça a Vegetação Brasileira. EDUSP, São Paulo. 165p.

Kraus, J.; Sousa, H.; Lanning, F.C.; Ponnaiya, W.X. \& Crumpton, C.F. 1958. The chemical nature of silica in plants. Plant Phhysiology 33: 339-343.

Leite, K.; França, F. \& Scatena, V.L. 2009. Anatomia de espécies anfíbias de Cyperaceae de lagoas do semi-árido, BA, Brasil. Acta Botanica Brasilica 23: 786-796
Martins, S.; Machado, S.R. \& Alves M. 2008. Anatomia e ultra-estrutura foliar de Cyperus maritimus Poir. (Cyperaceae): estratégias adaptativas ao ambiente de dunas litorâneas. Acta Botânica Brasílica 22: 493-503.

Mc Naughton, S.J. \& Tarrants, J.L. 1983. Grass leaf silification: natural selection for an inducible defense against herbivores. Proceedings of Natural Sciences 80: 790-791.

Mehra, P.N. \& Sharma, O.P. 1965. Epidermal silica cells in the Cyperaceae. Botanical Gazete 126: 53-58.

Menapace, F.J. 1990. A preliminary micromorphological analysis of Eleocharis (Cyperaceae) achenes for systematic potential. Canadian Journal of Botany 69: 1533-1541.

Menapace, F.J. \& Winjek, D.E. 1985. Scanning electron microscopy as an aid to the sectional placement of taxa within genus Carex (Cyperaceae): section Lupunieae and Visicarieae. Micron Microscopy Acta 16: 214-215.

Metcalfe, C.R. 1963. Comparative Anatomy as a Modern Botanical Discipline - with special reference to recent advances in the systematic anatomy of monocotyledons. Advances in Botanical Research 1: 101-147.

Metcalfe, C.R. 1969. Anatomy as an aid to classifying the Cyperaceae. American Journal of Botany 56: 782-790.

Metcalfe, C.R. 1971. Anatomy of the Monocotyledons. V. Cyperaceae. Clarendon Press, Oxford. 596p.

Moore, D. 1984. The distribution of opaline silica bodies in the leaf sheaths of two perennial ryegrass cultivars differing in their susceptibility to attack by dipterous stem-borers. Grass and Forage Science 39: 205-208.

Muasya, A.M.; Bruhl, J.; Simpson, D.A.; Culham, A. \& Chase, M.W. 2000. Suprageneric phylogeny of Cyperaceae: a combined analysis. In: Wilson, K. \& Morrison, D. (eds). Monocots Systematics and Evolution. CSIRO Publishing, Melbourne. Pp. 593-601.

Parkhurst, D.F. 1978. The adaptative significance of stomatal occurrence on one or both surfaces of leaves. Journal of Ecology 66: 367-383.

Prata, A.P.; Thomas, W. \& Wanderley, M.G. 2008. Micromorfologia da superfície do aquênio em Bulbostylis Kunth (Cyperaceae). Revista Brasileira de Botânica 31: 587-596.

Prychid, C.J.; Rudall, P.J. \& Gregory, M. 2004. Systematics and biology of silica bodies in Monocotyledons. The Botanical Review 69: 377-440.

Pyykkö, M. 1966. The leaf anatomy of East Patagonia xeromorphic plants. Annales Botanici Fennici 3: 435-622.

Rajbhandari, K.R. \& Obha, H. 1988. Epidermal microstructures of leaf, prophyll and nut in the Himalayan species of Kobresia (Cyperaceae). The Botanical Magazine of Tokyo 185: 185-202. 
Salo, V.; Pykala, J. \& Tovoinen, H. 1994. Achene epidermis in the Carex flava complex studied by scanning electron-microscopy. Annales Botanici Fennici 31: 45-52.

Santos, M.F.; Serafim, H. \& Sano, P.T. 2011. Fisionomia e composição da vegetação florestal na Serra do Cipó, MG, Brasil. Acta Botanica Brasilica 25: 793-814.

Silveira, M. 1989. Preparo de amostras biológicas para microscopia eletrônica de varredura. In: Souza, W. (ed.). Manual sobre técnicas básicas em microscopia eletrônica. Sociedade Brasileira de Microscopia Eletrônica, Rio de Janeiro. Pp. 71-90.

Simpson, D.A.; Furness, C.A.; Hodkinson, T.R.; Muasya, A.M. \& Chase, M.W. 2003. Phylogenetic relationships in Cyperaceae subfamily Mapanioideae inferred from pollen and plastid
DNA sequence data. American Journal of Botany 90: 1071-1086.

Soni, S.L., Kaufman, P.B. \& Bigelow, W.C. 1972. Electron microprobe analysis of silicon and other elements in developing silica cells of the leaf and internode of Cyperus alternifolius. Annals of Botany 36: 611-619.

Standley, L.A. 1987. Variation of stomatal distribution in Carex aquatilis (Cyperaceae). American Journal of Botany 73: 1393-1399.

Standley, L.A. 1990. Anatomical aspects of the taxonomy of sedges (Carex, Cyperaceae). Canadian Journal of Botany 68: 1449-1456.

Tovoinen, H. \& Timonen, T. 1976. Perigynium and achene epidermis in some species of Carex subgen. Vignea (Cyperaceae) studied by scanning electron microscopy. Annales Botanici Fennici 13: 49-59. 